\title{
Effect of Mg content on the density and critical properties of in-situ reacted $\mathrm{MgB}_{2}$ bulk superconductor
}

\author{
Byung-Hyuk Jun ${ }^{*}$, Dan-Bi Kim, Soon-Dong Park, and Chan-Joong Kim
}

Korea Atomic Energy Research Institute, Daejeon, Korea

(Received 5 February 2014; revised or reviewed 24 February 2014; accepted 25 February 2014)

\begin{abstract}
The effects of $\mathrm{Mg}$ content on the pore formation, density and critical properties were investigated in in-situ reacted $\mathrm{MgB}_{2}$ superconductors. The $\mathrm{Mg}_{1+\mathrm{x}} \mathrm{B}_{2},(\mathrm{x}=-0.2,0.0,0.05,0.3,1.0)$ bulk samples with different $\mathrm{Mg}$ contents were heat-treated at $900^{\circ} \mathrm{C}$ for $1 \mathrm{~h}$ in an Ar atmosphere. The dimensional changes of a pellet's mass and volume after heat-treatment were measured. After heat-treatment process, the sample mass was decreased by Mg evaporation, but the sample volume was expanded by pore formation at the $\mathrm{Mg}$ site; therefore, the apparent density was decreased. Spherical pores the same as $\mathrm{Mg}$ particles were developed after heat-treatment in all samples, and the pore density was increased with increasing Mg content. As the $\mathrm{x}$ of $\mathrm{Mg}$ content was increased to 1.0 , the apparent density of $\mathrm{Mg}_{1+\mathrm{x}} \mathrm{B}_{2}$ samples was decreased due to a relatively larger reduction in a mass change. The critical current density of $\mathrm{Mg}$ excessive sample of $\mathrm{x}=0.05$ showed the highest values over the applied magnetic fields because the excessive $\mathrm{Mg}$ may compensate $\mathrm{Mg}$ loss and enhance grain connectivity.
\end{abstract}

Keyword: $\mathrm{MgB}_{2}, \mathrm{Mg}$ content, in-situ reaction, pore, density, critical property

\section{1. 서 론}

$\mathrm{MgB}_{2}$ 초전도체는 초전도 임계온도 $\left(T_{\mathrm{c}}\right)$ 가 $39 \mathrm{~K}$ 로 기존의 $\mathrm{NbTi}_{1}, \mathrm{Nb}_{3} \mathrm{Sn}$ 저온 화합물 초전도체에 비해 높다. 이는 고가의 액체헬륨을 냉매로 사용하지 않고 20-25 $\mathrm{K}$ 에서 동작하는 냉동기를 사용하여 초전도 기기를 제작할 수 있다는 것을 의미하며 이로부터 초전도 자석의 설계가 쉬워지고 온도 마진이 커서 운영 효율을 높일 수 있다. 20 $\mathrm{K}$ 에서 가동되는 $\mathrm{MRI}$ 용 초전도 자석과 초전도 전력 응용기기에 적용하기 위하여 우수한 임계전류 특성을 갖는 $\mathrm{MgB}_{2}$ 선재 개발 연구가 진행 중이다. $\mathrm{MgB}_{2}$ 는 $\mathrm{REBCO}$ 고온 초전도체와 달리 초전도 특성을 결정하는 변수인 초전도 결맞음 길이 (superconducting coherence length)가 상대적으로 길고 weak link가 없다는 장점을 갖고 있다. $\mathrm{MgB}_{2}$ 의 초전도 특성을 향상시키고자 탄소 또는 탄소 화합물을 도핑물질로서 첨가하여 $\mathrm{B}$ 자리를 치환하는 연구가 많이 진행되어 왔고 [1-5] 더불어 저온 열처리 공정을 이용하여 $\mathrm{MgB}_{2}$ 결정립 크기를 작게 만들어 grain boundary pinning을 향상시키는 연구가 보고되었다 [6].

일반적으로 $\mathrm{MgB}_{2}$ 초전도체는 두 가지 공정으로 제작될 수 있다. 우선 in-situ 공정이란 $(\mathrm{Mg}+\mathrm{B})$ 분말을 사용하여 벌크나 선재 형태로 성형하고 열처리 공정을 통하여 $\mathrm{MgB}_{2}$ 초전도체를 제조하는 방법이다. 두 번째는 ex-situ 공정으 로 in-situ 공정으로 제조된 $\mathrm{MgB}_{2}$ 벌크를 분쇄하고 그 분 말을 사용하여 다시 열처리 공정을 거쳐 선재나 벌크 형태 의 $\mathrm{MgB}_{2}$ 초전도체를 제조하는 방법이다. Ex-situ 공정은 초기 분말 입자 크기를 제어하기 쉽고 기공이 없는 치밀한 $\mathrm{MgB}_{2}$ 미세조직과 높은 밀도를 얻을 수 있지만, $\mathrm{MgB}_{2}$ 자체 의 강도가 높아 가공이 어렵고 탄소 도핑효과도 낮아 in-situ 공정에 비해 임계전류밀도가 낮다는 단점이 있다. 무엇보다도 일단 깨진 $\mathrm{MgB}_{2}$ 입자간의 결합력은 재 열처리

\footnotetext{
* Corresponding author: bhjun@kaeri.re.kr
}

후에도 회복되기가 어렵기 때문에 통전 전류 특성이 좋지 않 다. 반면 in-situ 공정은 $\mathrm{Mg}$ 와 $\mathrm{B}$ 의 혼합분말을 이용하여 가 공이 쉽고 열처리 후 $\mathrm{MgB}_{2}$ 입자들끼리의 결합이 강하고 $J_{\mathrm{c}}$ 값이 높지만 $\mathrm{Mg}$ 확산 또는 용융으로 인한 많은 기공이 포 함되어 밀도가 낮은 단점이 있다.

$I_{n}-\operatorname{situ}$ 반응의 경우 $\mathrm{Mg}$ 자리는 기공으로 남게되며 녹는 점이 낮은 이유로 $\mathrm{Mg}$ 의 기화현상이 일어나 열처리 반응후 시편의 질량이 감소한다고 알려져 있다. 따라서 본 연구에 서는 $\mathrm{Mg}$ 과 $\mathrm{B}$ 의 조성비율에 따른 영향을 알아보고자

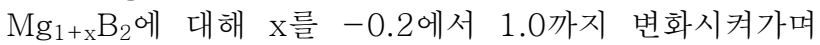
$900^{\circ} \mathrm{C}$ 의 $\mathrm{Mg}$ 용융점 이상에서 in-situ 반응 열처리 하였고 벌크내 기공 생성, 밀도 및 임계온도, 임계전류밀도등에 미 치는 $\mathrm{Mg}$ 함량 효과를 연구하였다.

\section{2. 실험방법}

그림 1 은 본 연구에서 사용된 $\mathrm{Mg}$ 과 $\mathrm{B}$ 분말의 주사전자 현미경 사진이다. 구형의 $\mathrm{Mg}$ 은 $99 \%$ 순도를 갖고 있으며 입 자 크기는 4-6 $\mu \mathrm{m}$ 이었다. B 분말의 순도는 95-97\% 이 며 입자 크기는 $1 \mu \mathrm{m}$ 이하였다. $\mathrm{Mg}$ 과 B 분말 모두 중국산 으로 Tangshan Weihao Magnesium Powder Co. 사에서

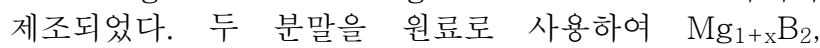
$(\mathrm{x}=-0.2,0.0,0.05,0.3,1.0)$ 조성 의 분말을 정량하여 각 각 30 분 동안 핸드믹싱 하였다. 혼합된 $\mathrm{Mg}_{1+x} \mathrm{~B}_{2}$ 분말을 $0.3 \mathrm{~g}$ 씩 정량하여 지름이 $10 \mathrm{~mm}$ 인 금속 몰드에 넣은 다음 일축 가압하여 벌크를 성형하였다. $\mathrm{Mg}$ 의 산화를 최소화 하 고자 성형된 벌크를 $\mathrm{Ti}$ 튜브안에 봉하여 $\mathrm{Ar}$ 분위기로에서 열처리를 실행하였다. 열처리 온도와 시간은 각각 $900^{\circ} \mathrm{C}, 1$ 시간이었다.

$\mathrm{MgB}_{2}$ 벌크의 상 분석을 위해 XRD를 사용하였다. In-situ 공정상 기공 생성에 따른 밀도 변화를 알아보고자 열처리 


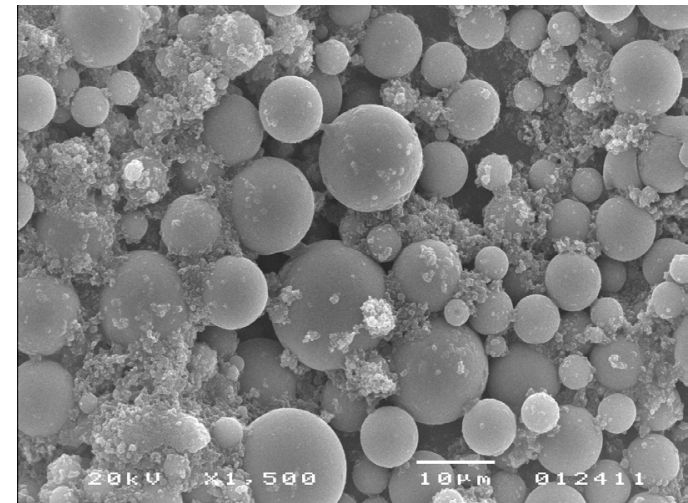

(a)

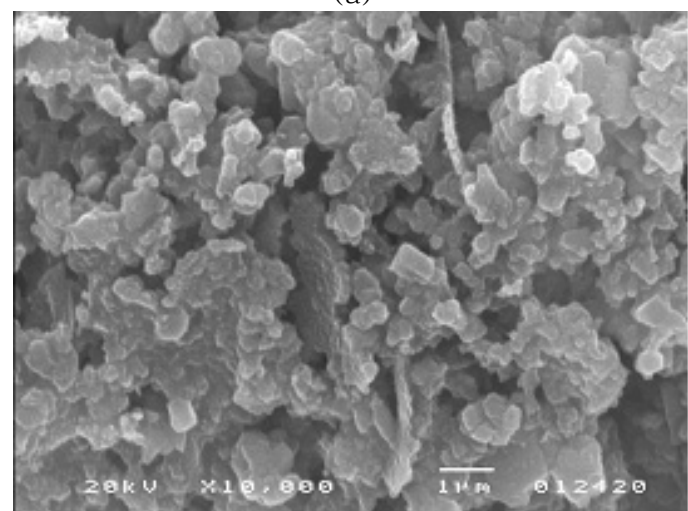

(b)

Fig. 1. Microstructure of raw material powders; (a) $\mathrm{Mg}$ powder and (b) B powder.

전과 후 시편의 질량과 부피를 측정하였다. 밀도는 시편의 질량을 부피로 나눈 겉보기 밀도로 시편내의 개 기공과 폐 기공 모두를 포함하는 값이다. 벌크 내 기공 형상과 분포등 미세조직을 관찰하기 위하여 주사전자현미경을 사용하였다. 열처리가 끝난 샘플에 대해 초전도 특성을 분석하기 위하여 각 시편을 직육면체 형태로 절단하였다. MPMS (Magnetic Property Measurement System) 기기를 사용하여 20-40 K 범위에서 시편의 자기 모멘트를 측정하여 임계온 도를 측정하였고, $5 \mathrm{~K}$ 과 $20 \mathrm{~K}$ 각각의 온도에서 0-7 T의 자기장을 인가하여 얻어진 magnetization loop를 통해 $\Delta$ $\mathrm{M}$ 을 측정하고 Bean model을 사용하여 임계전류밀도 $\left(J_{\mathrm{c}}\right)$ 를 계산하였다.

\section{3. 결과 및 고찰}

그림 2 는 $\mathrm{Mg}$ 조성에 따른 XRD 패턴을 보여주고 있는데 $900^{\circ} \mathrm{C}$ 에서 1 시간 열처리된 $\mathrm{Mg}_{1+{ }_{x}} \mathrm{~B}_{2}$ 는 $\mathrm{Mg}$ 조성에 관계 없이 $\mathrm{MgB}_{2}$ 상이 잘 성장되었다. 부차적으로 $\mathrm{MgO}$ 상이 관 찰되었는데 $\mathrm{Mg}$ 함량이 증가함에 따라 조금씩 증가하는 경 향을 보여주었다. $\mathrm{Mg}$ 은 미량의 산소와도 반응해 산화가 매 우 쉽게 되는 물질로서 자연 산화막을 갖고 있을 뿐만 아니 라 $\mathrm{B}$ 분말의 $\mathrm{B}_{2} \mathrm{O}_{3}$ 가 $\mathrm{Mg}$ 과 반응하여 $\mathrm{MgO}$ 가 생성된다. 따 라서 $\mathrm{Mg}$ 양이 증가함에 따라 증가하는 것으로 생각된다. 한 편 $\mathrm{Mg}$ 이 과량 첨가된 $\mathrm{Mg}_{2.0} \mathrm{~B}_{2}$ 시편의 경우에만 매우 작은 $\mathrm{Mg}$ peak이 남아 있었다.

$\mathrm{Mg}$ 함량에 따른 열처리 전과 후의 질량, 부피 및 밀도의 변화를 각각 그림 $3,4,5$ 에 나타내었다. $900^{\circ} \mathrm{C}$ 에서 열처
리 시 $\mathrm{Mg}$ 의 기화에 의하여 열처리 후 벌크의 질량은 감소 하였다. $\mathrm{x}=0.3,1.0$ 의 경우와 같이 $\mathrm{Mg}$ 이 많이 첨가된 경우 에는 $900^{\circ} \mathrm{C}, 1$ 시간 열처리 과정에서 $\mathrm{B}$ 과 반응하지 않고 남 은 과량 $\mathrm{Mg}$ 의 기화가 더욱 활발해 질 것으로 예상되며 질 량 감소가 큰 폭으로 나타났다. 상 분석시 $\mathrm{x}=0.3$ 또는 1.0 의 과량 $\mathrm{Mg}$ 첨가시에도 잔류하는 $\mathrm{Mg}$ peak는 거의 없는 것 으로 보아 $\mathrm{Mg}$ 기화가 상당량 일어남을 알 수 있었다. 한편 용융된 $\mathrm{Mg}$ 은 $\mathrm{B}$ 과 반응하면서 $\mathrm{MgB}_{2}$ 를 형성하고 $\mathrm{Mg}$ 자리 는 기공으로 남게 되어 시편의 부피는 증가하게 된다. $\mathrm{x}=0.05$ 까지 질량, 부피 및 밀도 변화의 폭이 크지 않았지 만 $\mathrm{Mg}$ 함량이 증가함에 따라 $\mathrm{x}=0.3$ 이상의 조성에서는 질 량의 큰 감소에 의해 밀도가 크게 감소함을 알 수 있었다. 참 고로 $\mathrm{Mg}$ 함량이 증가함에 따라 열처리 전과 후 모두 시편 부 피는 감소하는 경향을 보이고 있는 반면 $\mathrm{Mg}$ 함량 증가로 인 하여 열처리 전과 후 사이의 부피 팽창율은 증가하고 있음 을 알 수 있다.

열처리 전과 후, $\mathrm{MgB}_{2}$ 벌크에 대하여 각각의 질량, 부피 그리고 밀도 변화율을 계산한 결과를 Table I에 나타내었 다. 먼저 $\mathrm{x}=0.3, \mathrm{x}=1.0$ 의 경우, 질량 감소율은 각각 $7.98 \%$

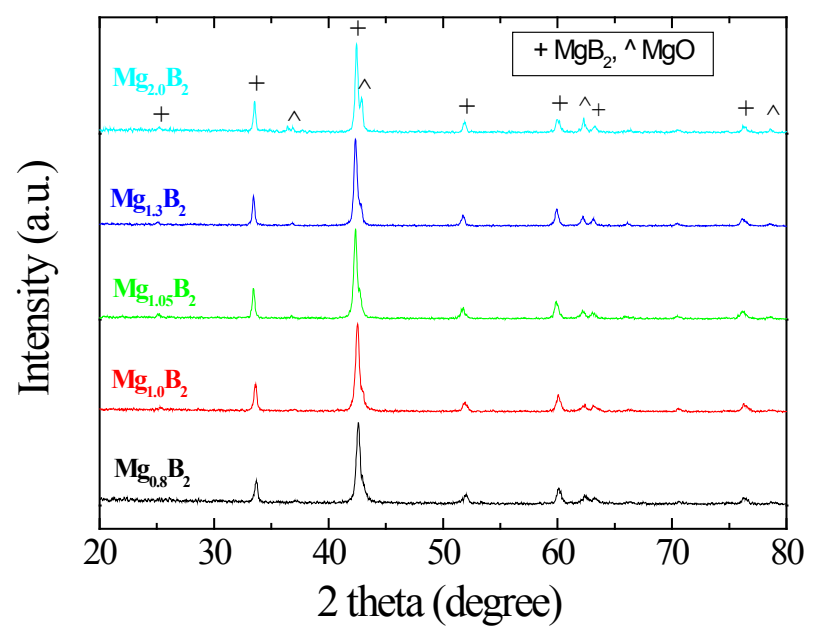

Fig. 2. XRD patterns of the $\mathrm{Mg}_{1+\mathrm{x}} \mathrm{B}_{2}$ bulks heat-treated at $900^{\circ} \mathrm{C}$ for $1 \mathrm{~h}(\mathrm{x}=-0.2,0.0,0.05,0.3,1.0)$.

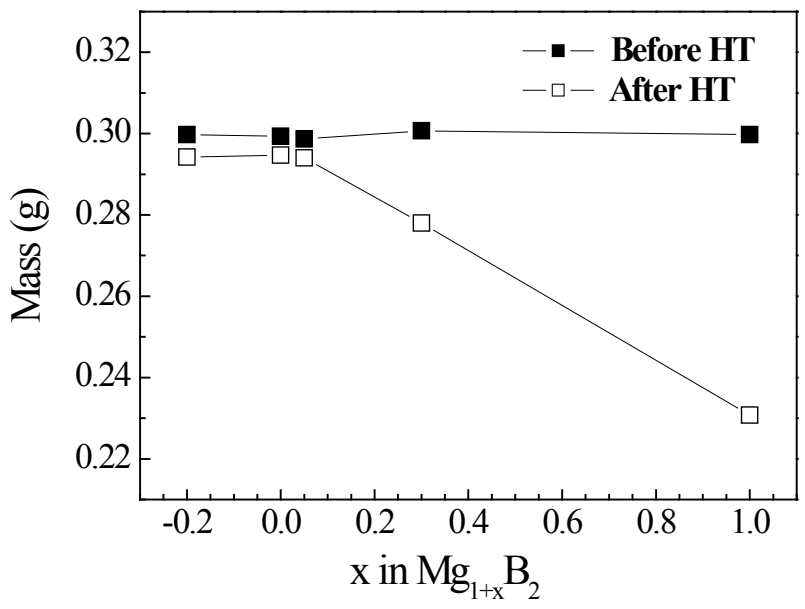

Fig. 3. Mass variation as a function of $\mathrm{Mg}$ content for the $\mathrm{Mg}_{1+\mathrm{x}} \mathrm{B}_{2}$ bulks before/after heat-treatment $(\mathrm{x}=-0.2,0.0$, $0.05,0.3,1.0)$. 


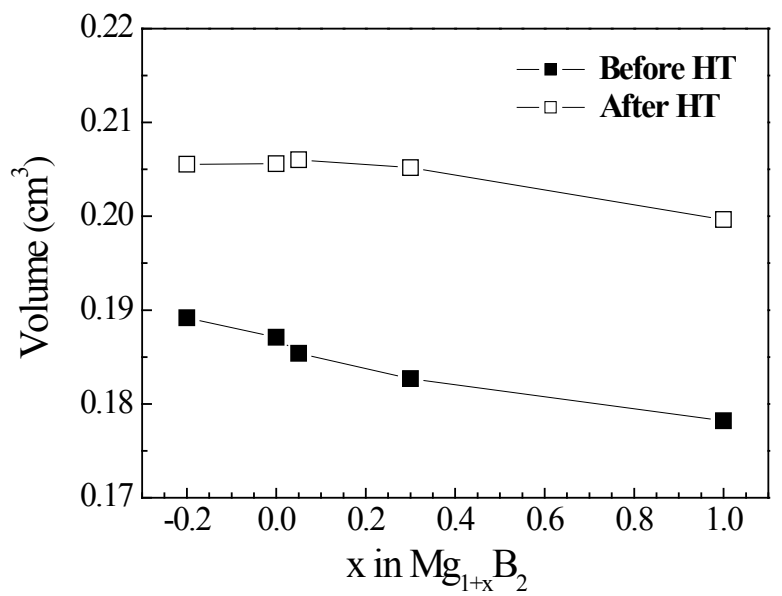

Fig. 4. Volume variation as a function of $\mathrm{Mg}$ content for the $\mathrm{Mg}_{1+\mathrm{x}} \mathrm{B}_{2}$ bulks before/after heat-treatment ( $\mathrm{x}=-0.2,0.0$, $0.05,0.3,1.0)$.

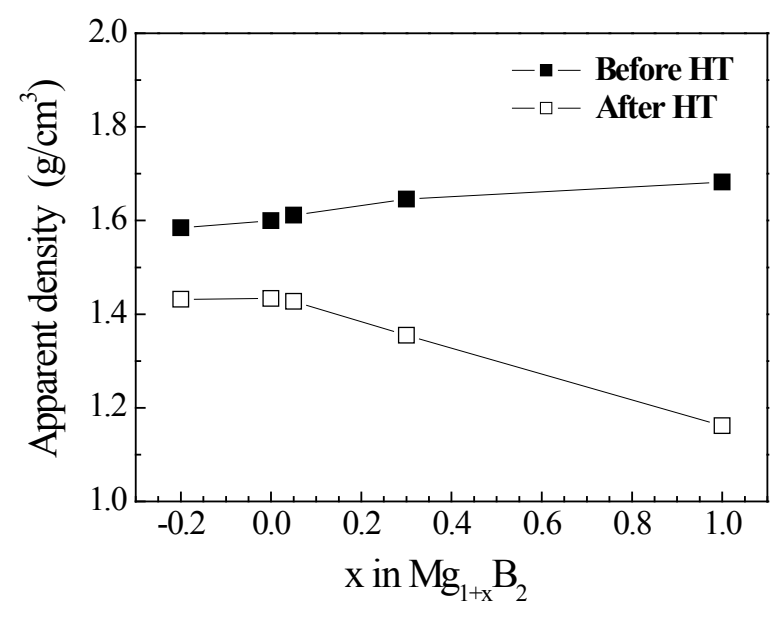

Fig. 5. Density variation as a function of $\mathrm{Mg}$ content for the $\mathrm{Mg}_{1+\mathrm{x}} \mathrm{B}_{2}$ bulks before/after heat-treatment ( $\mathrm{x}=-0.2,0.0$, $0.05,0.3,1.0)$.

TABLE I

MASS, VOLUME AND DENSITY VARIATION OF THE $\mathrm{Mg}_{1+\mathrm{x}} \mathrm{B}_{2}$ BULKS HEAT-TREATED AT $900^{\circ} \mathrm{C}$ FOR $1 \mathrm{H}$.

\begin{tabular}{cccccc}
\hline $\mathrm{Mg}$ 함량 (x) & -0.2 & 0.0 & 0.05 & 0.3 & 1.0 \\
\hline $\begin{array}{c}\text { 질량 변화율 } \\
(\%)\end{array}$ & -1.83 & -1.55 & -1.56 & -7.98 & -23.01 \\
\hline $\begin{array}{c}\text { 부피 변화율 } \\
(\%)\end{array}$ & 8.65 & 9.89 & 11.13 & 12.31 & 12.03 \\
\hline $\begin{array}{c}\text { 밀도 변화율 } \\
(\%)\end{array}$ & -9.65 & -10.41 & -11.43 & -17.67 & -30.88 \\
\hline
\end{tabular}

와 $23.01 \%$ 로 $\mathrm{x}=0,0.05$ 의 $1.55 \%$ 와 큰 차이를 보인다. 즉 $\mathrm{Mg}$ 양이 많을수록 열처리 중 $\mathrm{Mg}$ 의 기화에 의한 질량 감소 가 크며 이 질량 감소가 밀도 감소의 주된 원인이 됨을 알 수 있다. 부피의 경우, 열처리 후 펠렛의 팽창이 일어나며 이는 $\mathrm{Mg}$ 이 $\mathrm{B}$ 과 반응 후 그 자리가 기공으로 남기 때문이다. 비 록 과량의 $\mathrm{Mg}$ 은 증발하여 날아가기도 하지만 $\mathrm{Mg}$ 함량이 증 가함에 따라 부피 팽창율은 조금씩 증가하는 경향을 보였다.
한편, 겉보기 밀도의 변화를 보면 시편 모두 열처리 후에 밀 도가 감소된 것을 알 수 있다. 앞에서 언급한 바와 같이 밀 도의 감소는 반응후 팰렛 부피의 증가와 질량의 감소에 의 한다. 밀도 감소율이 $x=-0.2$ 일 경우 $9.65 \%, x=0.05$ 일 경 우 $11.43 \%$ 이었다가 $\mathrm{x}=0.3,1.0$ 일 경우에는 각각 $18 \%$, $31 \%$ 로 질량의 급격한 감소로 인하여 밀도 감소율이 크게 증가하였다.

그림 6 은 $900^{\circ} \mathrm{C}$ 에서 1 시간 열처리된 $\mathrm{Mg}_{1+x} \mathrm{~B}_{2}$ 벌크의 단 면 미세구조 사진을 보여주고 있다. 사용된 $\mathrm{Mg}$ 입자 모양과 동일한 구형의 기공을 포함하고 있으며 기공의 면적은 $\mathrm{Mg}$ 의 함량이 증가할수록 증가하는 경향을 보였다. 미세조직 사 진에서 기공의 면적 비율을 구해본 결과, $\mathrm{Mg}$ 의 첨가가 가장 적은 $\mathrm{x}=-0.2$ 시편의 기공의 면적 비율이 약 $23 \%$ 로 가장 낮았으며 $\mathrm{x}=1.0$ 으로 과도하게 $\mathrm{Mg}$ 을 첨가한 경우의 기공 분율은 약 $50 \%$ 로 $\mathrm{Mg}$ 의 함량이 증가함에 따라 기공 생성량 이 증가함을 알 수 있었다. 구형의 기공은 $900^{\circ} \mathrm{C}$ 열처리 승 온시 $\mathrm{Mg}$ 의 확산 및 용융으로 생성된다. $300{ }^{\circ} \mathrm{C} / \mathrm{h}$ 의 승온 속도로 열처리를 할 때, $650^{\circ} \mathrm{C}$ 의 $\mathrm{Mg}$ 용융점 이하에서부터 $\mathrm{Mg}$ 은 확산을 시작하고 용융점을 지나 승온하면서 용융된 $\mathrm{Mg}$ 은 capillary force로 빠르게 $\mathrm{B}$ 과 반응하여 $\mathrm{MgB}_{2}$ 를 생 성하고 $\mathrm{Mg}$ 자리에 기공을 남기게 된다.

그림 7은 $\mathrm{Mg}$ 함량을 변화시키며 제조된 $\mathrm{MgB}_{2}$ 벌크의 zero-field cooling 상태에서 측정된 온도-자기모멘트 곡 선을 나타낸다. $\mathrm{x}=-0.2$ 부터 $\mathrm{x}=0.3$ 까지의 $T_{\mathrm{c}}$,onset 값은 $37 \mathrm{~K}$ 로 거의 일정했고 천이 온도 폭도 작고 비슷하다. 반면 $\mathrm{x}=1.0$ 의 $T_{\mathrm{c}}$,onset값은 $35 \mathrm{~K}$ 로 낮았고 천이 온도 폭이 상당 히 큰데 이는 $\mathrm{MgB}_{2}$ 이외의 비초전도상의 존재로 인하여 $\mathrm{MgB}_{2}$ 결정성이 악화된 것에 기인한 것으로 판단된다.
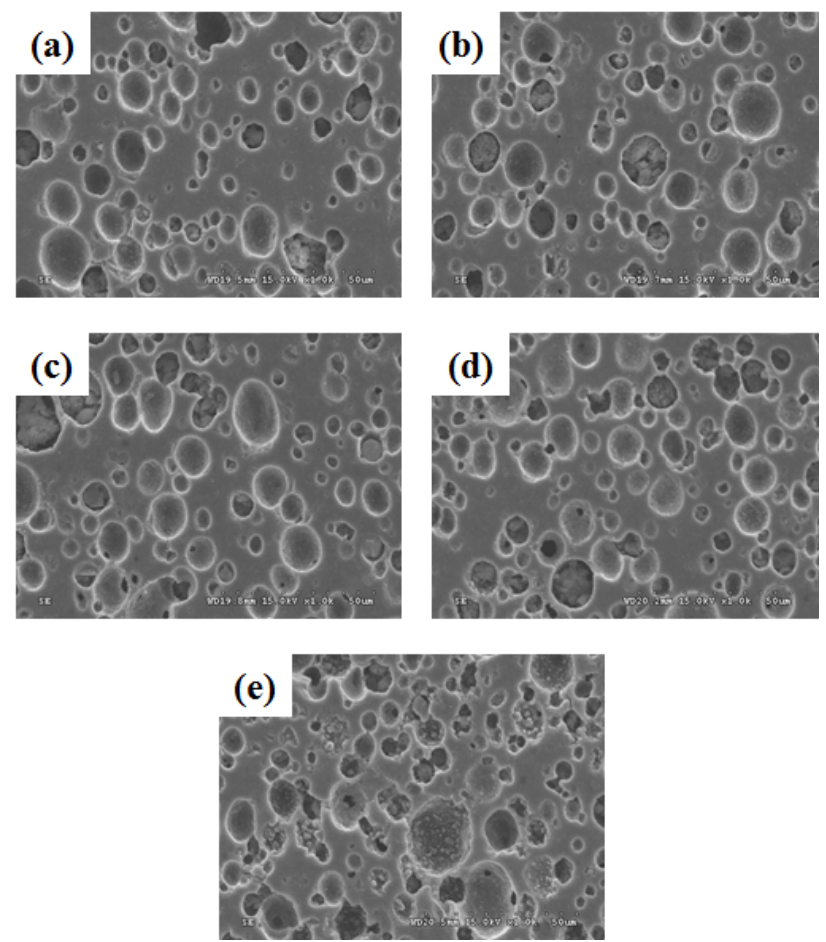

Fig. 6. Microstructure of $\mathrm{Mg}_{1+\mathrm{x}} \mathrm{B}_{2}$ bulks heat-treated at $900^{\circ} \mathrm{C}$ for $1 \mathrm{~h}$; (a) $\mathrm{x}=-0.2$, (b) $\mathrm{x}=0.0$, (c) $\mathrm{x}=0.05$, (d) $\mathrm{x}=0.3$, (e) $\mathrm{x}=1.0$. 


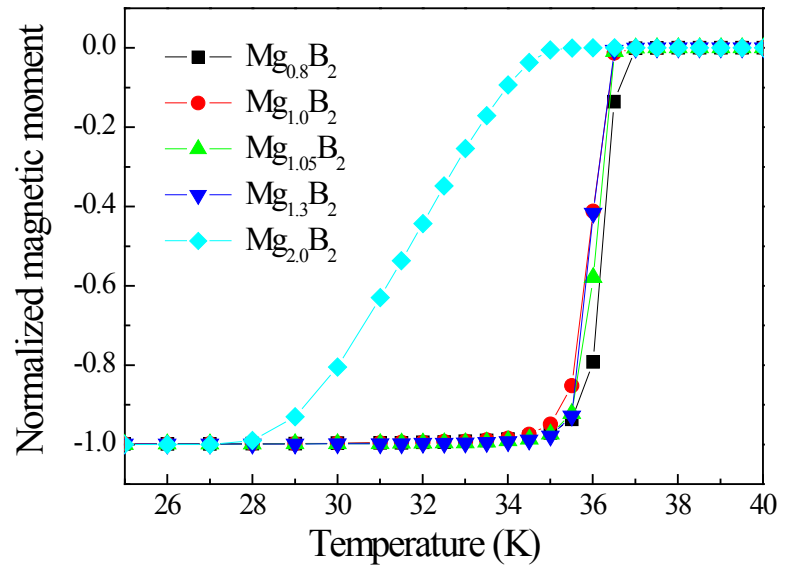

Fig. 7. Magnetic moment as a function of temperature for the $\mathrm{Mg}_{1+\mathrm{x}} \mathrm{B}_{2}$ bulks heat-treated at $900^{\circ} \mathrm{C}$ for $1 \mathrm{~h}$.

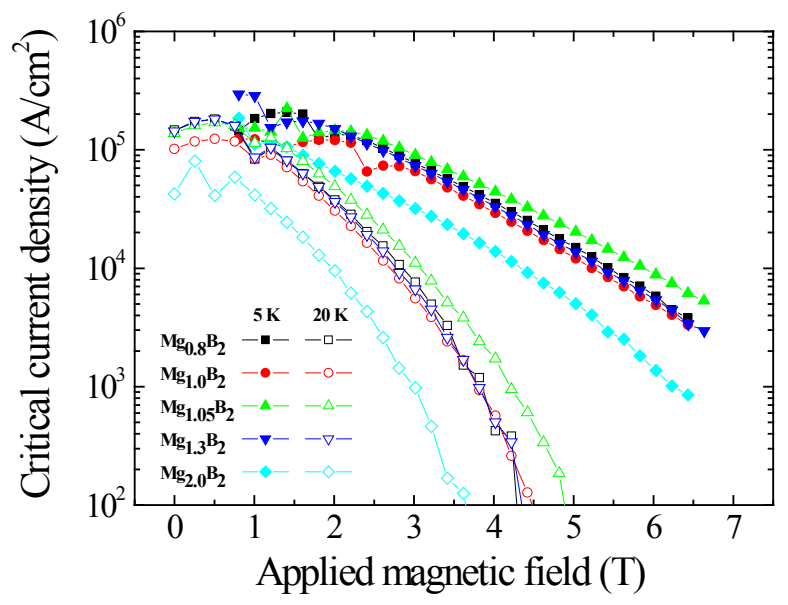

Fig. 8. Magnetic field dependence of $J_{\mathrm{c}}$ at 5 and $20 \mathrm{~K}$ for the $\mathrm{Mg}_{1+\mathrm{x}} \mathrm{B}_{2}$ bulks heat-treated at $900^{\circ} \mathrm{C}$ for $1 \mathrm{~h}$.

그림 8 은 $5 \mathrm{~K}$ 와 $20 \mathrm{~K}$ 에서 측정된 자기장-임계전류밀 도 특성을 보여준다. 두 온도 모두 $\mathrm{x}=0.05$ 일때 자기장에 따른 $J_{\mathrm{c}}$ 값이 가장 높았으며, $\mathrm{Mg}$ 을 과다 첨가한 $\mathrm{x}=1.0$ 조 성의 경우 임계전류밀도 값이 가장 낮았다. $\mathrm{x}=0$ 보다 $\mathrm{x}=0.05$ 에서 높은 $J_{\mathrm{c}}$ 를 보이는 이유는 소량의 과잉 $\mathrm{Mg}$ 첨 가가 $900^{\circ} \mathrm{C}$ 열처리 시 기화되는 $\mathrm{Mg}$ 의 손실을 보상해 주어 화학 정량비가 맞는 초전도 상이 이루어지고 결정립간의 연 결성 (grain connectivity)이 향상되기 때문인 것으로 여겨 진다 [7]. $\mathrm{x}=1.0$ 조성 시편의 낮은 $J_{\mathrm{c}}$ 는 감소된 $\mathrm{MgB}_{2}$ 초전 도상 부피와 밀도 그리고 상대적으로 증가된 $\mathrm{MgO}$ 비초전 도상에 기인하는 것으로 여겨진다.

\section{4. 결 론}

$\mathrm{Mg}$ 첨가량 변화에 따른 $\mathrm{Mg}_{1+\mathrm{x}} \mathrm{B}_{2}(\mathrm{x}=-0.2,0.0,0.05$, $0.3,1.0)$ 초전도체를 $900^{\circ} \mathrm{C}$ 에서 1 시간 동안 $\mathrm{Ar}$ 분위기 에서 in-situ 열처리 하였으며 기공생성과 질량, 부피, 겉보 기 밀도 및 임계 특성등의 변화에 관하여 연구하였다. 열처 리 후 $\mathrm{Mg}$ 의 기화 및 기공 생성으로 인하여 시편 질량은 감 소하고 부피는 증가하여 밀도는 감소하게 되었으며 과량의 $\mathrm{Mg}$ 첨가의 경우는 기화로 인한 질량 손실이 증가하면서 밀 도 감소율이 증가하였다. $\mathrm{Mg}$ 함량이 증가함에 따라 $\mathrm{MgB}_{2}$ 기공 밀도는 증가하였고 겉보기 밀도는 감소하였다. $\mathrm{Mg}_{1.05} \mathrm{~B}_{2}$ 조성의 경우가 가장 높은 임계전류밀도 값을 보여 주었는데 이는 소량의 $\mathrm{Mg}$ 첨가시 $\mathrm{Mg}$ 손실이 보상되고 grain connectivity가 증가되기 때문인 것으로 판단된다.

\section{ACKNOWLEDGMENT}

이 논문은 2013년도 정부 (미래창조과학부)의 재원으로 한국연구재단의 지원을 받아 수행된 연구입니다. (NRF-2013M2A8A1035822).

\section{REFERENCES}

[1] W. K. Yeoh and S. X. Dou, "Enhancement of $H_{\mathrm{c} 2}$ and $J_{\mathrm{c}}$ by carbon-based chemical doping," Physica C, vol. 456, pp. 170-179, 2007.

[2] R. H. T. Wilke, S. L. Bud'ko, P. C. Canfield and D. K. Finnemore, "Systematic Effects of Carbon Doping on the Superconducting Properties of $\operatorname{Mg}\left(\mathrm{B}_{1-\mathrm{x}} \mathrm{C}_{\mathrm{x}}\right)_{2}$," Phys. Rev. Lett., vol. 92, 217003, 2004.

[3] H. Yamada, M. Hirakawa, H. Kumakura and H. Kitaguchi, "Effect of aromatic hydrocarbon addition on in situ powder-in-tube processed $\mathrm{MgB}_{2}$ Tapes," Supercond. Sci. Technol. vol. 19, pp. 175-177, 2006.

[4] Y.-J. Kim, B.-H. Jun, K.S. Tan, B.G. Kim, J.M. Sohn, C.-J. Kim, "Effect of glycerin addition on the superconducting properties of $\mathrm{MgB}_{2}$," Physica C, vol. 468, pp. 1372-1374, 2008.

[5] K.S. Tan, S.K. Chen, B.-H. Jun, C.-J. Kim, "Enhancement in critical current density and irreversibility field of bulk $\mathrm{MgB}_{2}$ by $\mathrm{C}$ and $\mathrm{CaCO}_{3}$ co-addition," Supercond. Sci. Technol., vol. 21, 105013, 2008.

[6] B.-H. Jun, N.-K. Kim, K.S. Tan, C.-J. Kim, "Enhanced critical current properties of in situ processed $\mathrm{MgB}_{2}$ wires using milled boron powder and low temperature solid-state reaction," J. Alloys Compd., vol. 492, pp. 446-451, 2010.

[7] O. Perner, J. Eckert, W. Häßler, C. Fischer, J. Acker, T. Gemming, G. Fuchs, B. Holzapfel, and L. Schultz, "Stoichiometry dependence of superconductivity and microstructure in mechanically alloyed MgB 2 ,"J. Appl. Phys., vol. 97, 056105, 2005. 